\title{
Compression moulding of jute fabric reinforced thermoplastic composites based on PLA non-woven fabric
}

\author{
T. Katayama ${ }^{1,}$ K. Tanaka ${ }^{1}$, T. Murakami ${ }^{1}$ \& K. Uno ${ }^{2}$ \\ ${ }^{I}$ Department of Mechanical Engineering, Doshisha University, Japan \\ ${ }^{2}$ Marubeni Intex Co., Ltd., Japan
}

\begin{abstract}
To solve the problem of the large environmental burden in the disposal of FRP (Fibre Reinforced Plastics), natural fibre and biodegradable resin have received a lot of attention as easily degradable materials in the natural environment. To enlarge the usage of the composites based on natural fibre and biodegradable resin, cost reduction and enhancing its strength are essential subjects. In this study, in order to develop the environment friendly biodegradable composites that have high performance of strength, rigidity and productivity, the non-woven stacking method was proposed and the influence of moulding conditions on impregnating property and mechanical property of Jute Fabric Reinforced Thermoplastic composites (JFRTP) based on PLA non-woven fabric was discussed. It takes several minutes for PLA to impregnate into fibre bundles after the material reaches preset moulding temperature due to its high melt viscosity and twist of fibre bundles. The properly moulded JFRTP specimen reached about $115 \mathrm{MPa}$ in bending strength, which is comparable to GFRTP with $20 \mathrm{wt} \%$ long fiber made by injection moulding.
\end{abstract}

Keywords: green-composite, natural fibre, jute fibre, PLA, non-woven fabric, compression moulding, bending property.

\section{Introduction}

While growing interest in environmental issues, environmental burden of FRP disposal has been a big problem in recent years. The conventional materials for FRP, such as glass fibre or carbon fibre as reinforcement, and epoxy or polyamide as matrix are hardly degraded in natural environment and hardly 
incinerated due to their flame resistance. To settle this problem, the composites based on natural fibre and biodegradable resin, called 'Green-composite', have got a lot of attention as easily degradable materials in natural environment. To enlarge its usage, reducing the manufacturing cost and enhancing the strength are essential subjects.

For the reinforcement of the green composite, natural fibres, such as bamboo fibre, ramie, flax, kenaf jute, are used. Among these natural fibres, jute is one of superior materials due to its low cost, large amount of production and high specific strength and has got a lot of attention (Acha et al. [1]).

Polylactic acid (PLA) is usually used for the matrix of the green composite, because of its high strength, rigidity, melting point and productivity compared with other biodegradable resins. In the case of using PLA as matrix, film type PLA were usually used and they were laminated and moulded under compression with sheet type of reinforcing fibres, which is called 'Film Stacking', one of the well-applied impregnating methods of FRTP (Fibre Reinforced Thermoplastics) (Plackett et al. [2], Khondker et al. [3]). However, it is difficult to change the thickness of the film and handling of the film has also some problem, therefore a new impregnating method is expected to be developed. Non-woven fabric thermoplastic, which is used well for clothing, filter, diaper and so on, is applied as matrix resin in this study. Using non-woven fabric as matrix, mass per unit area or thickness can be easily changed. In this study, for the purpose of improving the productivity of not only Greencomposite but also conventional FRTP, we propose a impregnating 'Non-woven Stacking' method replaced by Film Stacking, in which reinforcing fibre sheets and matrix resin in the state of non-woven fabrics are laminated and moulded under compressive stress. Jute Fabric Reinforced Thermoplastics (JFRTP) using laminated jute plain woven fabrics and PLA non-woven fabrics were moulded under compressive stress and the influence of moulding time and moulding pressure on density and bending property were discussed.

\section{Experimental procedure}

\subsection{Materials and method}

Plain woven jute fabric (fig.1) of $430 \mathrm{~g} / \mathrm{m}^{2}$ is used for reinforcement and PLA non-woven fabric sheet (fig.2) made by melt-brown method is used as matrix in this study. The density, melting point and fibre diameter of PLA are $1.25 \mathrm{~g} / \mathrm{cm}^{3}$, $140^{\circ} \mathrm{C}, 2-3 \mu \mathrm{m}$, respectively.

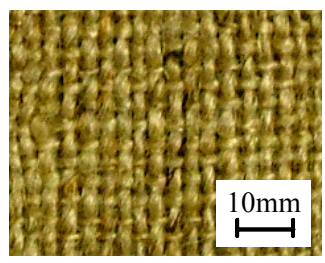

Figure 1: $\quad$ Plain woven Jute fabric. 


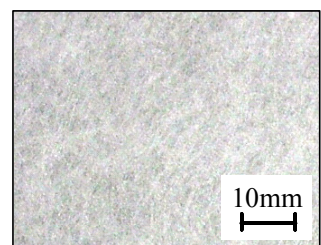

(a)

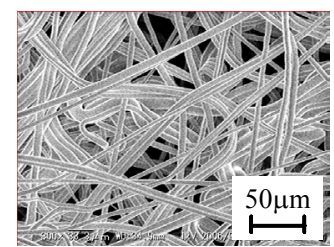

(b)

Figure 2: $\quad$ PLA non-woven fabric (a) Macroscopic photography and (b) Microscopic photography.

PLA non-woven fabric sheet is manufactured by melt-blown process. Figure 3 shows the schematic view of the melt-blown process. Melted resin with hot air is blown from the nozzles and non-woven sheet will be formed on the conveyer.

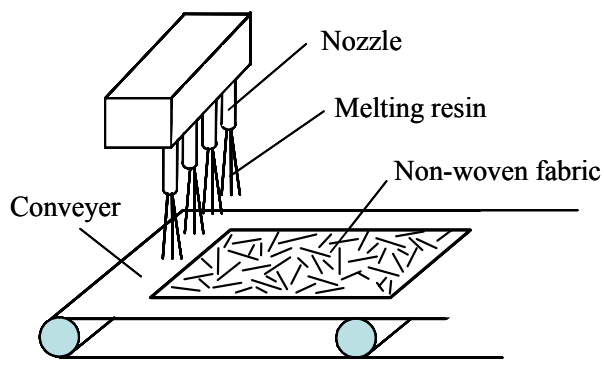

Figure 3: Meltblown process.

Compression moulding is carried out by vacuum press moulding machine. Jute fabrics in $450 \mathrm{~mm} \times 450 \mathrm{~mm}$ are stacked between four PLA non-woven fabrics in $450 \mathrm{~mm} \times 450 \mathrm{~mm}$ shown in fig. 4 . All the composites are processed at $48 \%$ fibre volume fraction. After setting the materials on the die, moulding is carried out under vacuum condition of $0.1 \mathrm{MPa}$. All the moulding conditions are shown in table 1. After moulding, the composites are air-cooled at laboratory temperature.

To evaluate the impregnation, density of the moulded product is measured and compared with theoretical density that is calculated under the assumption of no void in the composites.

\subsection{Mechanical testing}

Bending tests were conducted under a constant displacement rate of $1 \mathrm{~mm} / \mathrm{min}$ using an Instron 5566 universal testing machine. The length and width of the specimen are $60 \mathrm{~mm}$ and $15 \mathrm{~mm}$, respectively and three point bending tests were conducted at span length of $40 \mathrm{~mm}$. The thickness of the specimen depended on the moulding condition and varied from $1.8 \mathrm{~mm}$ to $3.1 \mathrm{~mm}$. 


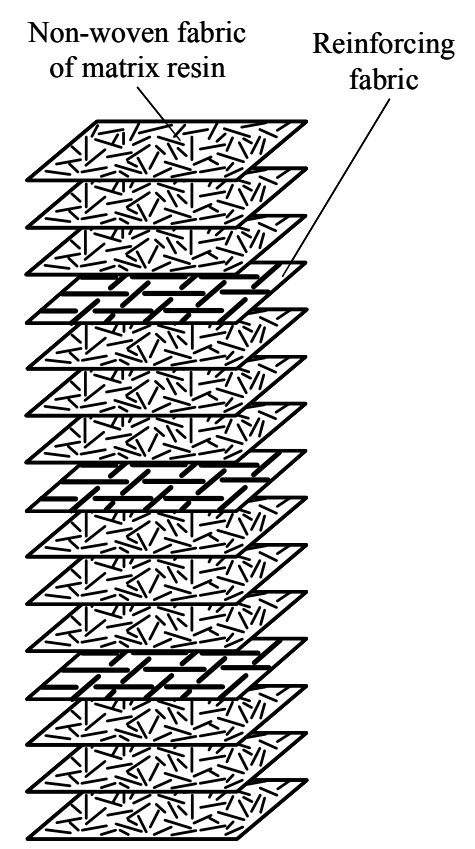

Figure 4: Laminated condition.

Table 1: $\quad$ Molding pressures and times.

\begin{tabular}{|c|c|c|c|c|c|c|}
\hline Pressure (MPa) & & 1.0 & 2.0 & 3.0 & 4.0 & \\
\hline Time (s) & 20 & $40 \quad 60$ & 120 & 180 & 300 & 600 \\
\hline
\end{tabular}

\section{Results and discussion}

\subsection{Impregnation}

The relationship between density and moulding time is shown in fig. 5. Before $60 \mathrm{~s}$, the density increases drastically irrespective of the moulding pressure. After $300 \mathrm{~s}$, however, it become stable and the density under moulding pressure of 3.0 $\mathrm{MPa}$ almost equal to that under 4.0 $\mathrm{MPa}$.

Figure 6 shows the cross section of the moulding product under the moulding pressure of $1.0 \mathrm{MPa}$, whose results shows more clearly the difference of moulding time on the impregnating state than other moulding pressure. Before $180 \mathrm{~s}$, many visible voids are observed. After $300 \mathrm{~s}$, however, matrix is impregnated into fibre bundles. This observation corresponds with the results of measured density change shown in fig. 4. Considering the fact that the higher moulding pressure than $3.0 \mathrm{MPa}$ and longer moulding time than $300 \mathrm{~s}$ don't 
affect so much on the density and impregnation, moulding pressure of $3.0 \mathrm{MPa}$ and moulding time of $300 \mathrm{~s}$ are optimum moulding value for the material used in our study.

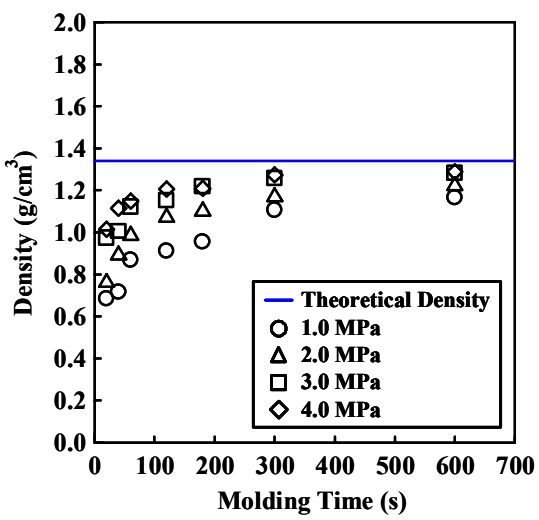

Figure 5: Relationship between density and moulding time.

Figure 7 shows the temperature change at the centre of the material during moulding under the moulding pressure of $1.0 \mathrm{MPa}$. After $10 \mathrm{~s}$ from the start of moulding, the material reaches the melting point of PLA $\left(140{ }^{\circ} \mathrm{C}\right)$ and after $60 \mathrm{~s}$ it becomes stable. In spite of the higher temperature than the melting point of PLA after $10 \mathrm{~s}$, it takes almost $300 \mathrm{~s}$ for PLA to impregnate into the fibre bundles. The high melt viscosity of PLA and the twist of jute fibre bundles are considered to be the reason for this.

\subsection{Bending property}

Figures 8 and 9 show the influence of moulding condition on the bending strength and the bending modulus, respectively. Before $300 \mathrm{~s}$, the bending strength and modulus drastically increase but after that they become stable. This behaviour is similar to the result of density shown in fig.5. From the viewpoint of the mechanical properties, moulding pressure of $3.0 \mathrm{MPa}$ and moulding time of $300 \mathrm{~s}$ are optimum moulding value.

Figure 10 shows the stress-displacement curve of bending test of the specimen moulded under pressure of 3.0 MPa. In the case of specimen moulded for $300 \mathrm{~s}$ and $600 \mathrm{~s}$, the bending stress is decreased rapidly after reaching the maximum value and they fractured in brittle manner. This behaviour is one of the evidence that the resin was impregnated into the fibre bundles.

Figures 11 and 12 show the comparison of the bending strength and modulus between our JFRTP and other materials. Injection moulded composite of glass fibre reinforced polypropylene with $20 \mathrm{wt} \%$ long fibre and jute fibre reinforced polypropylene with $51 \mathrm{wt} \%$ long fibre (Tanaka et al. [4]) are shown in these figures. The PLA/JF product in our study has better bending properties than GFRTP with 20 wt \% long fiber. 
164 High Performance Structures and Materials III

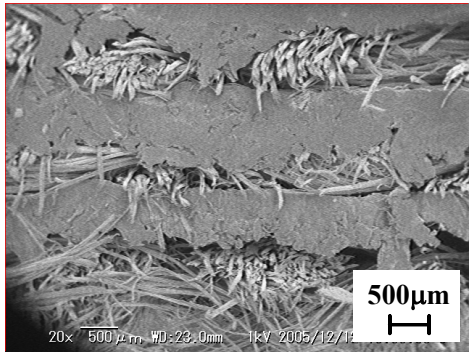

(a) $20 \mathrm{~s}$

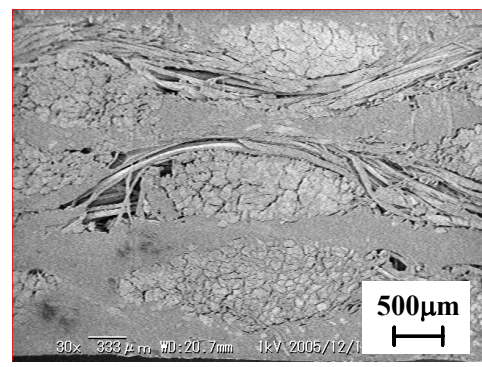

(c) $1 \mathrm{~min}$

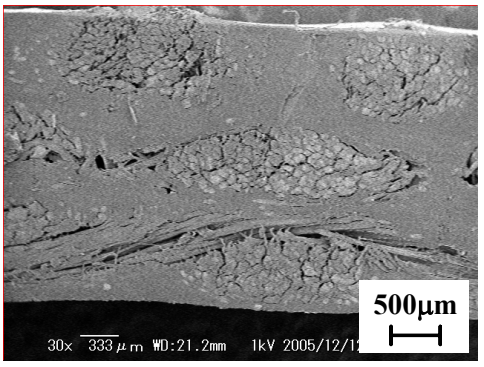

(e) $3 \mathrm{~min}$



(b) $40 \mathrm{~s}$



(d) $2 \mathrm{~min}$

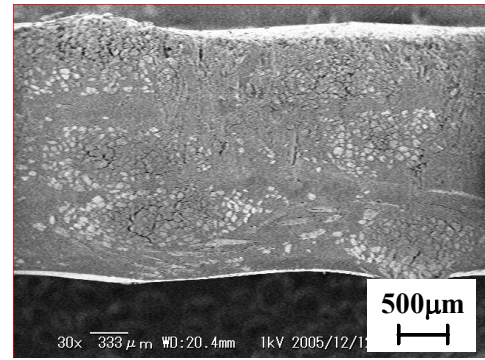

(f) $5 \mathrm{~min}$

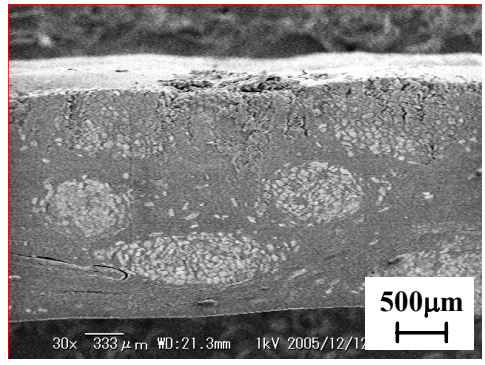

(g) $10 \mathrm{~min}$

Figure 6: Cross section photos of the moulded product (Moulding pressure: 1.0MPa). 


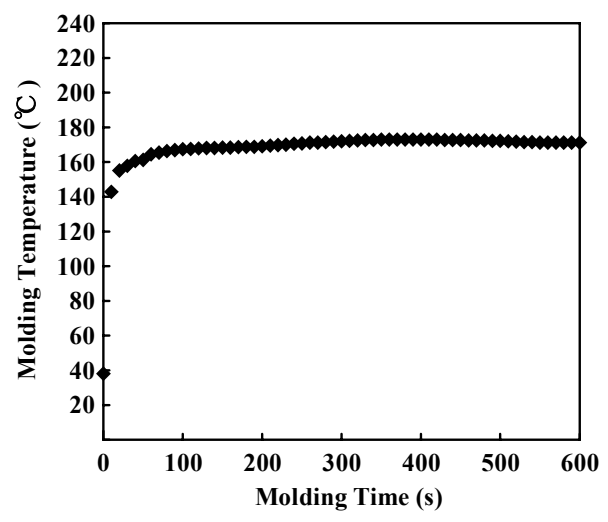

Figure 7: Temperature profile during moulding (moulding pressure: $1.0 \mathrm{MPa})$.

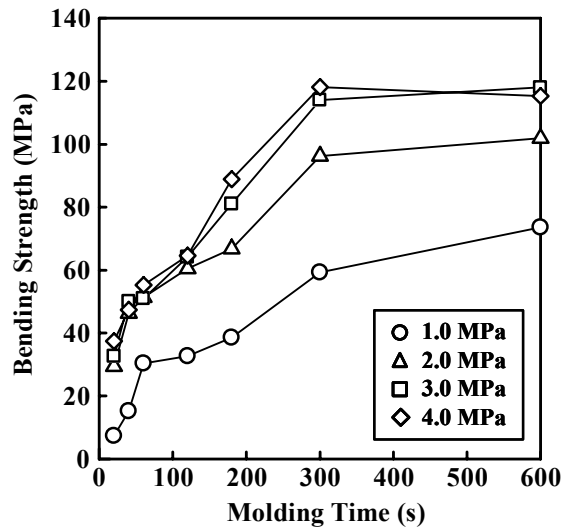

Figure 8: Relationship between bending strength and moulding time.

\section{Conclusions}

To develop the environment friendly biodegradable composites that have high strength and high productivity, "non-woven stacking" method was proposed and Jute Fabric Reinforced Thermoplastic composites (JFRTP) based on PLA nonwoven fabric were moulded and the influence of moulding conditions on impregnation and mechanical property was discussed. It takes several minutes for PLA to impregnate into fibre bundles after the material reaches preset moulding temperature, due to its high melt viscosity and twist of fibre bundles. The properly moulded JFRTP specimen reached about $115 \mathrm{MPa}$ in bending strength, which is comparable to GFRTP with $20 \mathrm{wt} \%$ long fiber made by injection moulding. 
166 High Performance Structures and Materials III

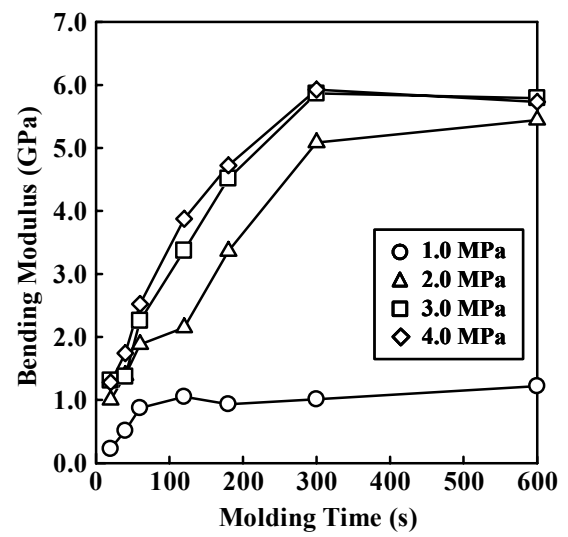

Figure 9: Relationship between bending modulus and moulding time.



Figure 10: Relationship between bending stress and displacement.

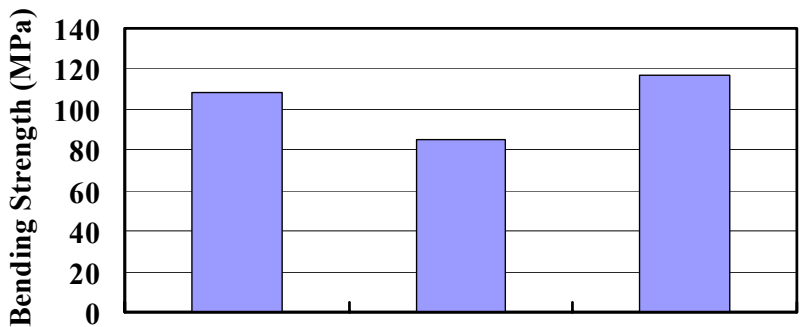

PP/GF 20wt\% PP/JF 51wt\% PLA/JF 53wt\% Long Fibre [4] Long Fibre [4] Plain Weave

Figure 11: Bending strength of the 3 types of FRTP [4]. 


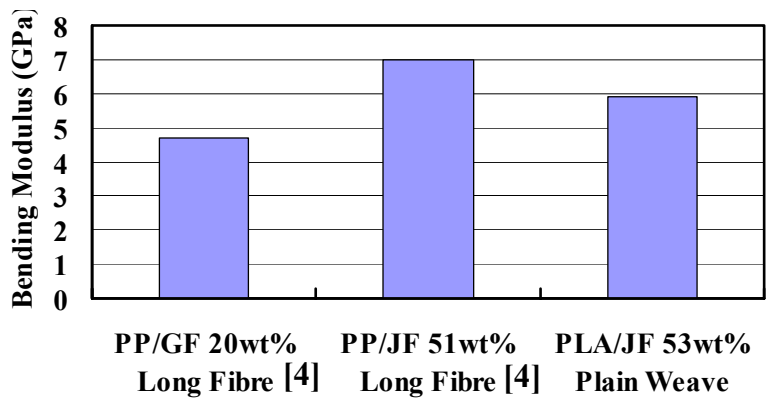

Figure 12: Bending modulus of the 3 types of FRTP [4].

\section{Acknowledgement}

This study was partially supported by the Academic Frontier Research Project on "NewFrontier of Biomedical Engineering Research" of Ministry of Education, Culture, Sports, Science and Technology.

\section{References}

[1] B.A. Acha, N.E. Marcovich, M.M. Reboredo, Journal of Applied Polymer Science, vol.98, No.2, (2005), pp.639-650.

[2] D. Plackett, T.L. Andersen, W.B. Pedersen, L. Nielsen, Composites Science And Technology, vol.63, No.9, (2003), pp.1287-1296.

[3] O.A. Khondker, U.S. Ishiaku, A. Nakai, H. Hamada, Journal of Polymers and the Environment, vol.13, No.2, (2005), pp.115-126.

[4] T. Tanaka, N. Tashiro, Japan Plastics, vol.56, No.7 (additional volume), (2005), pp.95-104. 